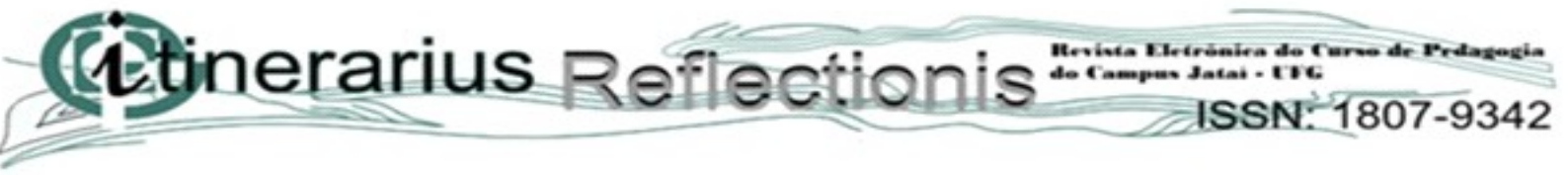

v.11, n. 1,2015

\title{
SAÚDE BUCAL NA EDUCAÇÃO INFANTIL, RESPONSABILIDADE DE QUEM?
}

\author{
LEITE, Giulena Rosa \\ Professora do Curso de Enfermagem, UFG- Regional Jataí \\ Doutoranda em Ciências da Saúde/UFG \\ giulenar@gmail.com \\ BRÁS, Suele de Moraes \\ Pedagoga, graduada pela UFG- Regional Jataí \\ sussuariel@hotmail.com \\ FALEIROS, Sônia Aparecida \\ Pedagoga, mestranda em Educação/UFG- Regional Jataí \\ sonnyafaleiros@yahoo.com.br \\ MAIA, Ludmila Grego \\ Professora do Curso de Enfermagem, UFG- Regional Jataí \\ Mestre em Enfermagem \\ lgregomaia@yahoo.com.br \\ MARTINS, Marlene Andrade \\ Professora do Curso de Enfermagem, UFG- Regional Jataí \\ Doutora em Enfermagem \\ marlenianapower@hotmail.com \\ SILVA, Luiz Almeida da \\ Professor do Curso de Enfermagem, UFG- Regional Jataí \\ Pós-doutorando em Enfermagem \\ enferluiz@yahoo.com.br
}

\section{Resumo}

Com o objetivo de avaliar o conhecimento em saúde bucal e a importância mostrada a este assunto por parte dos professores, foram entrevistados todos os 17 profissionais de um Centro Municipal de Educação Infantil no Município de Jataí, no sudoeste de Goiás. A coleta de dados se deu em dois momentos: inicialmente foi realizada uma observação livre a fim conhecer melhor os trabalhos desenvolvidos pelos educadores/professores desta instituição, uma imersão no campo de estudo. Em um segundo momento foi realizado entrevista com os profissionais da instituição, por meio de um roteiro estruturado, contendo perguntas abertas e fechadas sobre o tema. As ações de proteção e promoção a saúde, podem ser desenvolvidas pelo sistema de saúde, articulado com outras instituições governamentais, empresas, associações comunitárias e com a população e seus órgãos de representação visando à redução de fatores de risco, que constituem ameaça à saúde dos 


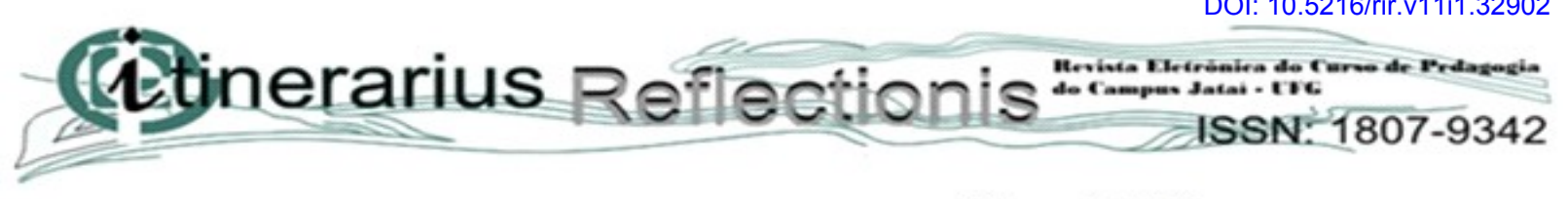

v.11, n. 1, 2015

indivíduos, podendo provocar-lhes incapacidades e doenças. Considerando a saúde bucal como parte integrante e indissociável da saúde geral, a infância é o período que pode ser considerado como o mais importante para o futuro da saúde bucal do indivíduo. Foram entrevistados 17 educadores, todos do sexo feminino, 13 eram naturais de Jataí/GO, 07 possuíam graduação completa e 13 eram casados. Em relação ao tempo de serviço, 10 educadoras possuíam tempo entre 11 e 21 anos, 11 indivíduos afirmaram não ter recebido qualquer informação a respeito de promoção da saúde bucal em sua formação e 16 referiram ter interesse em receber mais informações sobre esse assunto. Em relação a sua própria higiene bucal, 12 relataram ir regularmente ao dentista; porém, 15 relataram estar precisando desta consulta.

Palavras-chave: Saúde bucal. Educação Infantil. Promoção da Saúde.

\section{ORAL HEALTH IN EARLY CHILDHOOD EDUCATION, WHOSE RESPONSIBILITY?}

\section{Summary}

In order to evaluate the oral health knowledge and shown the importance of this issue in the teachers, were interviewed all 17 staff from a Municipal Kindergarten Centre in the city of Jataí, in the southwest of Goiás. The data collection was in two occasions: was initially performed a free observation in order to know better the work done by educators / teachers of this institution, an immersion in the field of study. In a second step we interviewed professionals in the institution, through a structured questionnaire with open and closed questions on the subject. The protective actions and health promotion, can be developed by the health system, combined with other government agencies, businesses, community organizations and the people and their representative bodies in order to reduce risk factors that constitute health threat of individuals, which could cause them disability and illness. Considering the oral health as an integral and inseparable part of general health, childhood is the period which can be considered as the most important for the future of oral health of the individual. We interviewed 17 teachers, all female, 13 were from Jataí / GO, 07 had complete undergraduate and 13 were married. With regard to length of service, 10 educators had time between 11 and 21 years 1 lindivíduos claimed to have received no information about oral health promotion in their training and 16 reported having interest in receiving more information about this subject. Regarding their own oral hygiene, 12 reported regularly go to the dentist; however, 15 reported being in need of this consultation.

Keywords: Oral health. Early Childhood Education. Health Promotion 


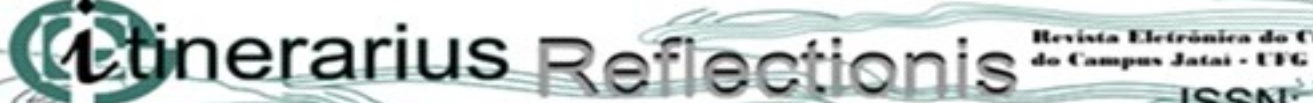 \\ ISSN:-1807-9342}

v.11, n. 1,2015

\section{INTRODUÇÃO}

Em 1954, a Comissão de Especialistas em Educação em Saúde da Organização Mundial da Saúde (OMS) colocou a necessidade de serem realizadas, dentro do espaço escolar, diversas atividades que favorecessem a promoção da saúde e não somente o trabalho de transmissão de conhecimentos sobre aspectos relacionados à saúde. Nesse sentido, foi apresentada uma abordagem inicial ao conceito de Escola Promotora de Saúde (OMS, 1954). As ações de proteção e promoção à saúde podem ser desenvolvidas pelo sistema de saúde, articulado com outras instituições governamentais, empresas, associações comunitárias e com a população e seus órgãos de representação. Tais ações visam à redução de fatores de risco, que constituem ameaça à saúde das pessoas, podendo provocar-lhes incapacidades e doenças.

A promoção de saúde bucal está inserida num conceito amplo de saúde que transcende a dimensão meramente técnica do setor odontológico, integrando a saúde bucal às demais práticas de saúde coletiva. Significa a construção de políticas públicas saudáveis, o desenvolvimento de estratégias direcionadas a todas as pessoas da comunidade, como políticas que gerem oportunidades de acesso à água tratada, incentive a fluoretação das águas, o uso de dentifrício fluoretado e assegurem a disponibilidade de cuidados odontológicos básicos apropriados. Ações de promoção da saúde incluem também trabalhar com abordagens sobre os fatores de risco ou de proteção simultâneos tanto para doenças da cavidade bucal quanto para outros agravos tais como: políticas de alimentação saudável para reduzir o consumo de açúcares, abordagem comunitária para aumentar o autocuidado com a higiene corporal e bucal, política de eliminação do tabagismo e de redução de acidentes (BRASIL, 2004)

Durante a realização das atividades práticas de estágio das alunas do curso de enfermagem e pedagogia, observou-se que grande parte das crianças não consegue sozinha fazer a sua higiene bucal fazendo-se necessária ajuda para realizar a escovação dos dentes, o que nem sempre tem acontecido prontamente por parte dos trabalhadores nas escolas. 


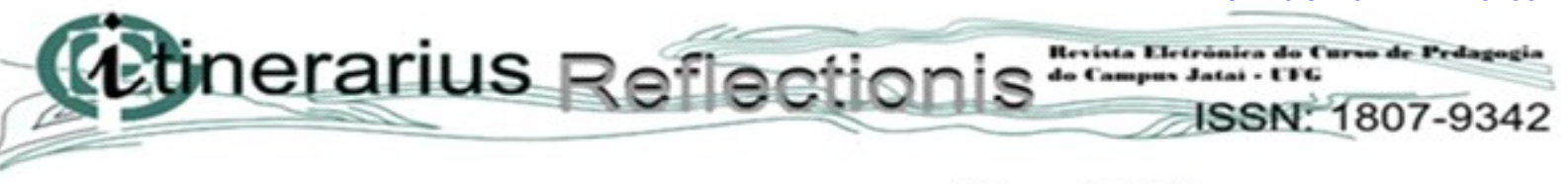

v.11, n. 1,2015

De acordo com Garcia et al. (2000, p.37) "a prevenção é a maneira mais econômica e eficaz de se evitar o aparecimento e desenvolvimento das principais doenças bucais". Dentro das várias atividades preventivas e promotoras da saúde, a educação e a motivação do indivíduo ocupam lugar de destaque e devem ser aplicadas com o objetivo de mudar hábitos e comportamentos, no sentido de promover a saúde e melhorar a higiene bucal do indivíduo. Ações de conscientização e valorização da saúde devem ser desenvolvidas desde a pré-escola, podendo incorporar em seus hábitos de vida os cuidados relativos à boca e aos dentes (FABRE et al., 1998).

A educação, por ser um instrumento de transformação social, propicia a reformulação de hábitos e a aceitação de novos valores, e neste caso, também a melhoria na auto-estima.

Desta maneira, o grande desafio é atuar junto aos professores da educação infantil, munindo-os de informações necessárias ao despertar para o incentivo ao desenvolvimento de hábitos saudáveis nessas crianças, prevenindo doenças bucais, numa mudança de atitude em relação a essas doenças que freqüentemente são tidas como inevitáveis.

Assim, com o objetivo de caracterizar o perfil sócio-demográfico dos professores/educadores que atuam em um Centro Municipal de Educação Infantil de Jataí e dimensionar o conhecimento desses profissionais sobre esse tema, bem como avaliar a importância que ofertam a realização da sua própria higiene bucal, esse trabalho se desenvolve.

1. Contextualização da saúde bucal na educação infantil: leis e políticas

A crescente participação da mulher no mercado de trabalho brasileiro, no intuito de auxiliar na manutenção econômica da família, com certeza é uma das mais marcantes mudanças na sociedade moderna.

Com o advento da modernidade e as mudanças sociais, a mulher de hoje raramente fica em casa para cuidar dos seus filhos. Com isso, desde muito cedo se torna interessante pensar a escola como um dos melhores lugares para o desenvolvimento da criança e uma opção para os cuidados dos filhos de mães trabalhadoras. 


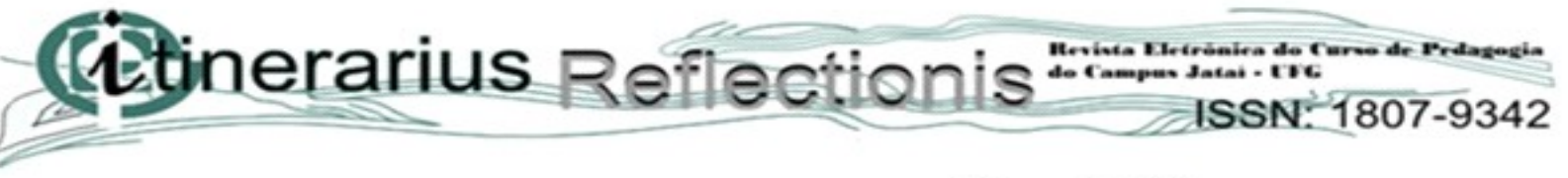

v.11, n. 1,2015

Os pais ou responsáveis estão escolhendo colocar as crianças ainda muito pequenas na escola e como as crianças permanecem grande parte do dia nessa instituição, acabam por passar para o professor e auxiliares da educação, a responsabilidade de educar e cuidar da criança.

Nas últimas décadas, os debates em nível nacional e internacional apontam para a necessidade de que as instituições de educação infantil incorporem de maneira integrada as funções de educar e cuidar, não mais diferenciando nem hierarquizando os profissionais e instituições que atuam com as crianças pequenas e / ou aqueles que trabalham com as maiores (BRASIL, 1998).

Há um tempo, as características assistencialistas e filantrópicas das instituições de educação infantil estavam muito presentes no nosso país uma vez que estas instituições em sua maioria eram ligadas às Secretarias De Promoção E Assistência Social dos municípios. Hoje em dia a educação infantil já evoluiu muito, existem objetivos educacionais explícitos, propostas pedagógicas e profissionais qualificados que buscam o melhor para a educação das crianças. A legislação é clara, todas as crianças têm o direito ao acesso a educação.

Com a Constituição Federal de 1988 passou a ser dever do Estado garantir a oferta de creche e a pré-escola às crianças de zero a seis anos de idade. Tomou-se por orientação que as instituições deveriam não apenas cuidar das crianças, mas desenvolver um trabalho educacional.

Em consonância aos princípios propostos na constituição federal, o Estatuto da Criança e do Adolescente - ECA, Lei 8069/1990, ratifica o direito a oferta de educação pelo Estado às crianças de zero a seis anos de idade, capítulo IV, art.54, inciso IV.

A Lei de Diretrizes e Bases da Educação Nacional (LDBEN), n. 9.396/96 contempla pela primeira vez o direito à educação infantil como responsabilidade do setor educacional, caracteriza a Educação Infantil (creche e pré-escola) como primeira etapa da Educação Básica. Segundo essa legislação, a creche deve atender as crianças de zero até três anos de idade e a préescola, as crianças de 4 a 6 anos de idade.

Atendendo às determinações da LDBEN que estabelece, pela primeira vez na história de nosso país, que a educação infantil é a primeira etapa da educação básica; foi elaborado o 


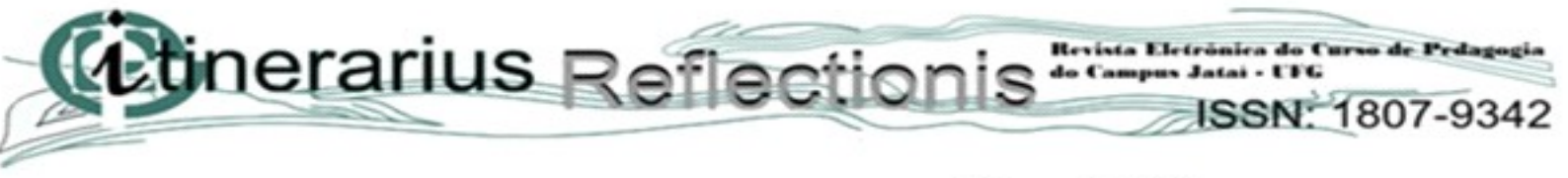

v.11, n. 1,2015

Referencial Curricular Nacional para a Educação Infantil (RCNEI) referente às creches, entidades equivalentes e pré-escolas.

Esse referencial pretende apontar metas de qualidade que contribuam para que as crianças tenham um desenvolvimento integral de suas identidades, capazes de crescerem como cidadãos cujos direitos à infância são reconhecidos. Visa, também, contribuir para que possa realizar, nas instituições, o objetivo socializador dessa etapa educacional, em ambientes que propiciem o acesso e a ampliação, pelas crianças, dos conhecimentos da realidade social e cultural (pág. 7)

Dividido em três volumes, o Referencial foi concebido de maneira a servir como um guia de reflexão de cunho educacional sobre objetivos, conteúdos e orientações didáticas para os profissionais que atuam diretamente com crianças de zero a seis anos, respeitando seus estilos pedagógicos e a diversidade cultural brasileira.

Os RCNEIs, em seu volume 1, abrangem questões relativas à saúde do individuo, referindo que os cuidados são compreendidos como aqueles referentes à proteção, saúde e alimentação, incluindo as necessidades de afeto, interação, estimulação, segurança e brincadeiras que possibilitem a exploração e a descoberta (BRASIL, 1998). Expõe ainda que o desenvolvimento integral dependa tanto dos cuidados relacionais, que envolvem a dimensão afetiva e dos cuidados com os aspectos biológicos do corpo, como a qualidade da alimentação e dos cuidados com a saúde, quanto da forma como esses cuidados são oferecidos e das oportunidades de acesso a conhecimentos variados (BRASIL, 1998).

O Referencial propõe ainda que:

Os procedimentos de cuidado também precisam seguir os princípios de promoção à saúde. Para se atingir os objetivos dos cuidados com a preservação da vida e com o desenvolvimento das capacidades humanas, é necessário que as atitudes e procedimentos estejam baseados em conhecimentos específicos sobre o desenvolvimento biológico, emocional, e intelectual das crianças, levando em consideração as diferentes realidades socioculturais (pág. 25). 


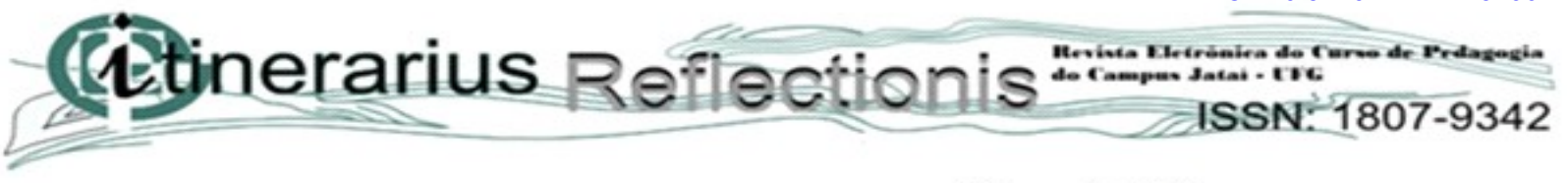

v.11, n. 1,2015

Descobrir e conhecer progressivamente seu próprio corpo, suas potencialidades e seus limites, desenvolvendo e valorizando hábitos de cuidado com a própria saúde e bem-estar; é um objetivo da educação infantil citado no volume 1 do RCNEI.

$\mathrm{O}$ fato de muitas instituições atenderem em horário integral implica uma maior responsabilidade quanto ao desenvolvimento e aprendizagens infantis, assim como com a oferta de cuidados adequados em termos de saúde e higiene. Estes horários estendidos devem significar sempre maiores oportunidades de aprendizagem para as crianças e não apenas a oferta de atividades para passar o tempo ou muito menos longos períodos de espera. Algumas informações devem ser colhidas previamente à entrada da criança na instituição, como os esquemas, preferências e intolerância alimentar; os hábitos de sono e de eliminação; os controles e cuidados especiais com sua saúde, etc.

Já o volume 2, nas questões relativas ao cuidado de crianças de zero a três anos, afirma que a higiene das mãos constitui-se um recurso simples e eficiente entre as atitudes e procedimentos básicos para a manutenção da saúde e prevenção de doenças e propõe a realização de pequenas ações cotidianas ao seu alcance para que adquira maior independência (BRASIL, 1998).

Sobre a higiene bucal, informa ainda que:

Considerando que a primeira dentição inicia-se, em geral, no segundo semestre de vida e que estará completa em torno dos três anos de idade, recomenda-se incluir este cuidado a partir do surgimento dos primeiros dentes. Os dentistas recomendam a limpeza dos dentes do bebê com uma gaze enrolada no dedo indicador do adulto responsável pelo cuidado. É importante evitar as práticas de oferecer mamadeiras para a criança antes de ela dormir, sem a posterior limpeza dos dentes, ou mesmo o uso de chupetas mergulhadas em mel ou açúcar para acalmar as crianças, pois isso pode provocar cáries muito precoces. Como a criança aprende muito pela observação e imitação é importante que ela presencie adultos e outras crianças fazendo sua higiene bucal, ao mesmo tempo que poderão ampliar seus conhecimentos sobre esses cuidados (pág. 56).

2. Higiene dentária na educação infantil 


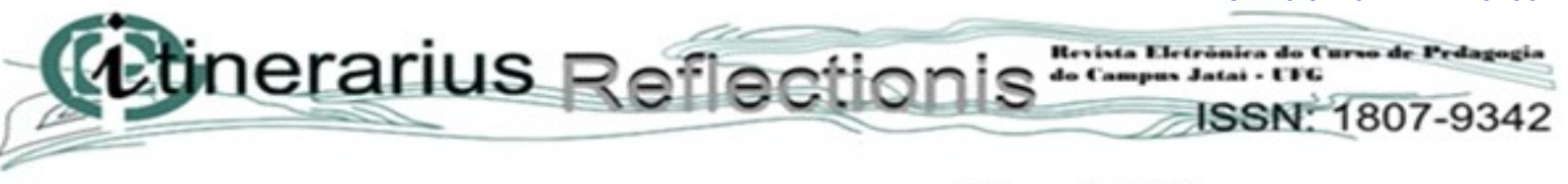

v.11, n. 1,2015

Os primeiros dentes começam a fazer parte da vida da criança aproximadamente aos seis meses de idade, completando a sua dentição mais ou menos aos três anos de idade. A primeira dentição são os dentes decíduos.

Segundo Brasil (1998), “considerando que a primeira dentição inicia-se, em geral, no segundo semestre de vida e que estará completa em torno dos três anos de idade a partir dos surgimentos dos primeiros dentes" (p.56), faz-se de grande importância o cuidado com a dentição nessa faixa etária.

Muitos pais acreditam que não é necessário ter os cuidados com os dentes decíduos, conhecidos por muitos como dentes de leite, deixando de lado os cuidados necessários que se deve ter com a higiene bucal da criança. Esses cuidados devem ser iniciados desde a gestação da mãe e continuados até romperem todos os dentes e por toda a vida, evitando as cáries, placas e tártaros.

A primeira dentição é composta por 20 dentes; 10 inferiores e 10 superiores. É importante que o responsável pela criança procure orientações sobre a primeira dentição da criança, como fazer essa higiene, que cuidados são necessários para se evitar a cárie. Em Brasil (1998), “os dentistas recomendam a limpeza dos dentes do bebê com uma gaze enrolada no dedo indicador do adulto responsável pelo cuidado" (p.56).

Logo quando a criança nasce é necessário que seja alimentada. Para tanto, lhe é oferecido o leite materno que é recomendado com alimento exclusivo nos primeiros seis meses de vida da criança. O mesmo é considerado alimento completo e rico em vitaminas protegendo assim a criança de algumas doenças.

Não é necessário que se ofereça à criança outros alimentos e objetos para sucção. É indispensável que a cada momento que a criança mame seja feita a limpeza com água filtrada e gazes na boca da criança, evitando assim; que a criança venha a ter cárie na sua primeira dentição.

De acordo com Brasil (1998),

É importante evitar as práticas de oferecer mamadeiras para a criança antes de ela dormir, sem posterior limpeza dos dentes, ou mesmo o uso de chupetas mergulhadas em 


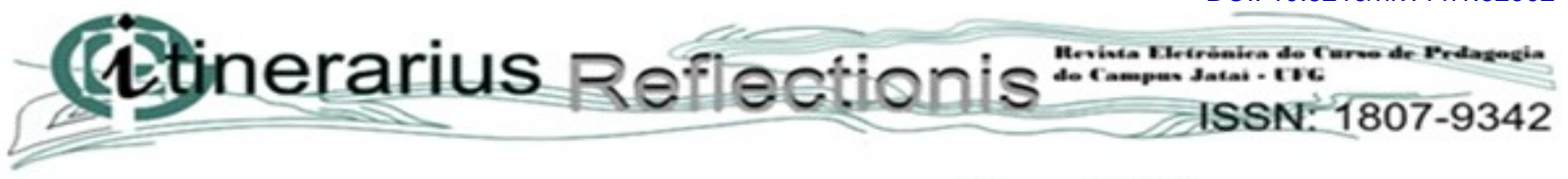

v.11, n. 1,2015

mel ou açúcar para acalmar as crianças, pois isso pode provocar cáries muito precoces (p. 56).

Aproximadamente aos seis meses de vida a criança já consegue sentar-se sozinha, é neste momento que os responsáveis podem começar a colocar a escova na sua mão para que comece a se familiarizar com o objeto que deverá ser adequado à idade da criança. Esse momento pode ser durante o banho e no momento em os adultos realizam a sua própria higiene bucal, assim a criança vai perceber que é importante cuidar dos dentes.

De acordo com Brasil (1998), "como a criança aprende muito pela observação e imitação é importante que ela presencie adultos e outras crianças fazendo sua higiene bucal, ao mesmo tempo que poderão ampliar seus conhecimentos sobre esses cuidados” (p. 56).

Quando a criança vai para a escola esse cuidado continua sendo feito pelo educador, ensinando a criança a importância de se cuidar dos dentes. Brasil, no periodo em que a criança esta sob os cuidados da instituição educativa é possivel prever uma rotina de escovação dos dentes, visando desenvolver atitudes e construir habilidades para autocuidado com a boca e com os dentes (BRASIL, 1998, p. 57).

Nessa primeira fase da infância iniciam se a formação de hábitos saudáveis. Brasil (1998) referem que

A instituição de educação infantil deve tornar acessível a todas as crianças que frequentam, indiscriminadamente, elementos da cultura que enriqueçam o seu desenvolvimento e inserção social. Cumpre um papel socializado, propiciando o desenvolvimento da identidade das crianças, por meio de aprendizagens diversificadas, realizadas em situações de interação (p. 23).

E afirmam ainda que

Educar pode tornar- se para o educador e a criança um momento prazeroso. Educar significa, portanto, propiciar situações de cuidados, brincadeiras e aprendizagens orientadas de forma íntegra e que possam contribuir para o desenvolvimento das capacidades infantis de relação interpessoal, de ser, e estar com os outros em uma atitude básica de aceitação, respeito e confiança, e o acesso, pelas crianças, aos conhecimentos mais amplos da realidade social e cultural (p. 23). 


\section{(4tinerarius Reflectionis:=" =:

No processo de ensino e aprendizagem o educador/professor precisa colocar em seu conteúdo curricular e planejamentos diários, momentos de interação, que seria o brincar com a criança, neste momento podendo assim passar um filme, desenhos, revista, gibis e outras atividades que faça com que a criança possa expressar as suas emoções.

A criança que não brinca não aprende, não tem interesse nem entusiasmo, não demonstra sensibilidade e não desenvolve afetividade. As brincadeiras são reconhecidas como linguagem da criança, uma maneira que utilizam para expressar-se e demonstrar sentimentos.

Segundo Brasil (1998), a brincadeira favorece a auto-estima das crianças, auxiliando-as a superar progressivamente suas aquisições de forma criativa. Brincar contribui, assim para a interiorização de determinados modelos de adulto, no âmbito de grupos sociais diversos. Essa significação atribuída ao brincar transforma- no em um espaço singular de constituição infantil.

Os cuidados com a saúde bucal podem ser ensinados de maneira lúdica e criativa. Durante as atividades recreacionais, há a possibilidade de abordar o tema de maneira divertida fazendo com que a criança perceba a importância do ato e que internalizar a ação como sendo algo natural e de necessidade para seu dia a dia.

\section{Metodologia}

Trata-se de estudo quantitativo, realizado em um dos Centros Municipais de Educação Infantil - CEMEI - de Jataí, sudoeste de Goiás, tendo como população os profissionais educadores desta instituição.

A coleta de dados se deu em dois momentos: inicialmente foi realizada uma observação livre a fim conhecer melhor os trabalhos desenvolvidos pelos educadores/professores desta instituição, uma imersão no campo de estudo. Em um segundo momento foi realizado uma entrevista com os profissionais da instituição, por meio de um roteiro estruturado, contendo 


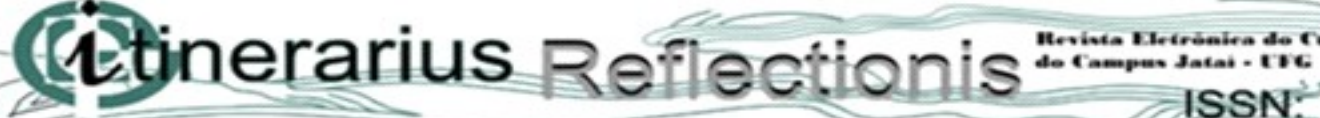
2

v.11, n. 1,2015

perguntas abertas e fechadas sobre o tema. O presente estudo não ofereceu nenhum tipo de risco para qualquer indivíduo, pois consistiu apenas na resposta à entrevista; além disso, apresenta benefício científico, apontando diretrizes a serem seguidas no que diz respeito à promoção da saúde bucal no município de Jataí.

Inicialmente o projeto foi apresentado ao Secretário de educação de Jataí e ao diretor do CEMEI e solicitada suas autorizações para a execução da pesquisa. Em seguida, esse projeto foi apresentado e submetido à aprovação do Conselho Diretor do Campus Jataí e encaminhado ao Comitê de Ética em Pesquisa da Universidade Federal de Goiás, para autorização de implementação.

As informações obtidas foram registradas de modo a não permitir a identificação dos participantes, sendo adotado um nome fictício a cada participante. Antes de iniciar o estudo, o Termo de Consentimento Livre e Esclarecido (TCLE) foi apresentado e assinado pelo participante, conforme regulamenta os dispositivos da Resolução 466 do Conselho Nacional de Saúde (BRASIL, 2012).

A coleta se deu entre os meses de julho e agosto de 2013 e a amostra constou de todos os 17 profissionais educadores da instituição. Todos os dados coletados foram armazenados em um banco de dados e analisados utilizando o pacote Statistical Package for the Social Science (SPSS) versão 17 para análise da estatística descritiva, as quais estão apresentadas em forma de tabelas e figuras. O projeto foi aprovado pelo Comitê de ética da UFG, sob inscrição na Plataforma Brasil número 26368314.2.0000.5083.

\section{Resultados e Discussões}

Considerando a saúde bucal como parte integrante e indissociável da saúde geral, a infância é o período que pode ser considerado o mais importante para o futuro da saúde bucal do indivíduo. Na infância, as noções e os hábitos de cuidados com a saúde devem começar a se formar 


\section{(ctinerarius Reflectionis

(ALALUUSUA e MALMIVIRTA, 1994), permitindo assim que as ações educativas mais tarde baseiem-se no reforço de rotinas já estabelecidas.

As atividades extraclasses são responsáveis por grande parte da aprendizagem dos alunos, apesar de muitos já chegarem imbuídos de valores como ordem, limpeza, higiene, trabalho persistente, etc. Para tanto passa a ser necessário o professor agir como agente transformador e formador de opiniões e por que não dizer, agente promotor da saúde.

O professor é um educador em saúde não só quando desenvolve os conteúdos do currículo, mas também de maneira não formal ao realizar projetos, observar as necessidades emergentes dos alunos ou participar de campanhas que visem promover o bem estar e a saúde da comunidade escolar.

A Tabela 1 apresenta as características sócio-demográficas dos educadores que participaram desta pesquisa. Foram entrevistados todos os profissionais educadores da instituição totalizando 17 entrevistas. Destes, 17 eram do sexo feminino, 13 eram naturais de Jataí/GO e 13 eram casados.

TABELA 1 - Características sócio-demográficas de 17 educadores de um CEMEI em Jataí, sudoeste goiano, 2013.

\begin{tabular}{lcc}
\hline Característica & $\mathbf{N}$ & $\mathbf{\%}$ \\
\hline Sexo & & \\
Feminino & 17 & 100 \\
Masculino & 00 & 00 \\
\hline Idade & & \\
\hline $20-30$ & 1 & 5,9 \\
$31-40$ & 3 & 17,6 \\
$41-50$ & 8 & 47 \\
$51-60$ & 5 & 29,5 \\
$>60$ & 00 & 00 \\
\hline Escolaridade & & \\
\hline Magistério & 02 & 11,7 \\
$2^{0}$ grau completo & 01 & 5,9 \\
Graduação completa & 07 & 41,2 \\
Graduação incompleta & 01 & 5,9
\end{tabular}




\begin{tabular}{lcc} 
Pós graduação Latu sensu & 05 & 29,4 \\
Mestrado & 01 & 5,9 \\
\hline Naturalidade & & \\
\hline Jataí & 13 & 76,5 \\
Outros municípios & 4 & 23,5 \\
\hline Estado Civil & & \\
\hline Solteira & 03 & 17,6 \\
Casada & 13 & 76,5 \\
Viúva & 01 & 5,9 \\
\hline$\quad$ Total & 17 & 100 \\
\hline
\end{tabular}

Quanto à análise da escolaridade, observou-se que sete educadores possuíam graduação completa, inclusive com cinco possuíam Pós Graduação Latu sensu, fato que evidencia bom atendimento às normas estabelecidas para o ensino na educação básica.

A LDB em seu artigo 62 determina que a formação de docentes para atuar na educação básica far-se-á em nível superior, em curso de licenciatura, de graduação plena, em universidades e institutos superiores de educação, admitida, como formação mínima para o exercício do magistério na educação infantil e nos 5 (cinco) primeiros anos do ensino fundamental, a oferecida em nível médio na modalidade normal. Sendo assim, todos os profissionais se classificam dentro desta expectativa de formação (BRASIL, 1996).

Quanto ao tempo de serviço em educação, 4 educadores possuía tempo entre 1 e 10 anos de serviço; 10(59\%) educadores possuía tempo entre 11 e 21 anos de serviço e $3(18 \%)$ trabalhava há mais de vinte anos como educador, como pode ser visualizado na Figura 1. 


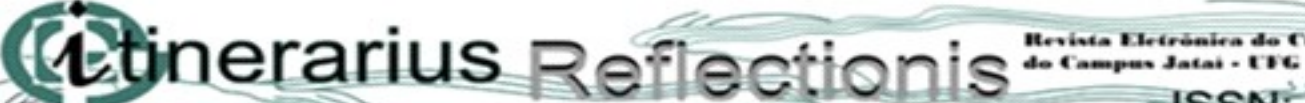

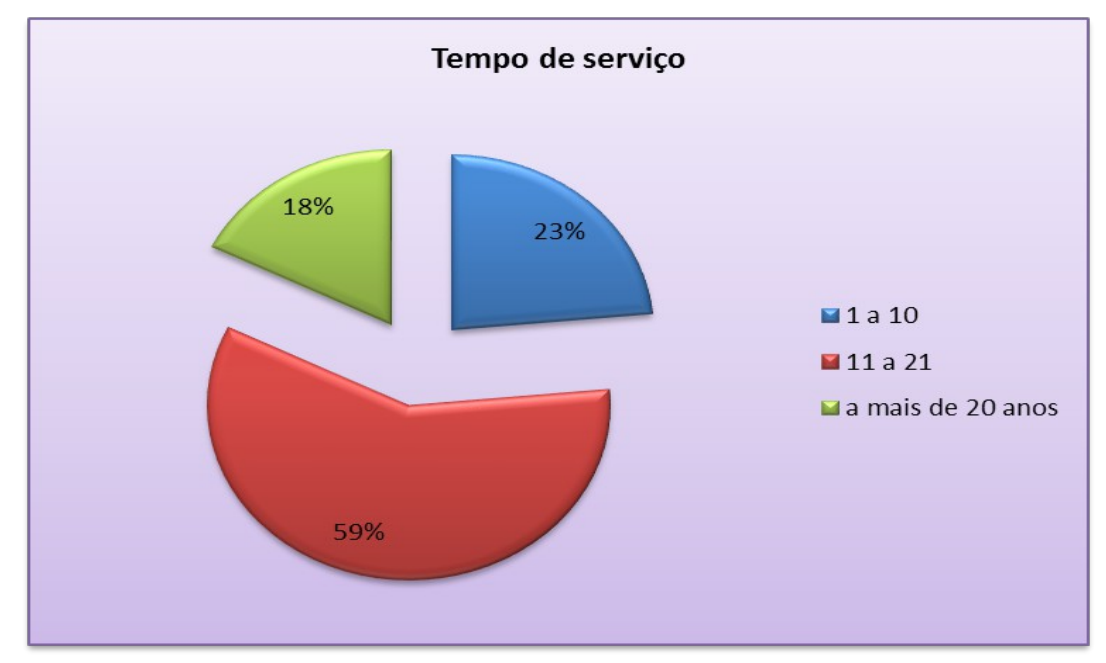

FIGURA 1. Classificação dos educadores de um CEMEI quanto ao tempo de serviço Jataí, sudoeste de Goiás, 2013.

Quando inquiridos a respeito de ter tido acesso a conteúdos ligados à saúde bucal em sua formação acadêmica, 11(64\%) afirmaram não ter recebido qualquer informação à esse respeito e 16 (94\%) referiram ter interesse em receber mais informações sobre saúde bucal.

Em relação à busca do seu conhecimento sobre Saúde Bucal, 10 educadoras apontam a televisão como fonte principal de informação, seis relatam que receberam informação da equipe de odontologia da Estratégia Saúde da Família (ESF) que atua na escola e um se refere à livros, revistas, músicas, teatro e informações que recebeu de sua própria família.

Vasconcelos et al. (2001) explicam que o fato de a escola discutir pouco os conceitos de saúde bucal se deve à falta de conhecimento sobre o assunto e escassez de tempo disponível. Assim, a inclusão dos conteúdos relacionados à saúde bucal nos currículos das escolas de educação infantil contribuiria para que a abordagem destes temas em salas de aula fosse mais aprofundada e freqüente. Esse mesmo estudo, semelhante ao nosso, reporta que 44\% dos participantes afirmaram ter acesso a informações sobre saúde bucal em sua formação acadêmica.

Ao serem indagadas a respeito da integração existente entre a Equipe de Odontologia da ESF e a escola, houve respostas que se mostraram contraditórias: 4 educadoras referiram que às 


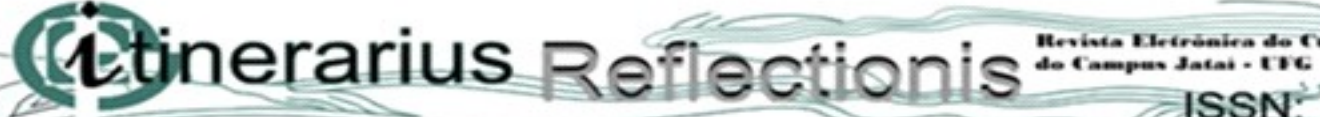

vezes isso acontece, 7 referiram que não acontece e 6 que acontece sim a integração entre as duas equipes.

A Estratégia Saúde da Família (ESF) tem se tornado o principal alavancador da reorganização dos serviços de saúde na atenção básica, incluindo-se a Saúde Bucal. Tem como principais estratégias a promoção da saúde, prevenção e recuperação, com atenção voltada para a família. A Saúde Bucal como parte desse processo, tem sido abordada pelas equipes de ESF dentro das escolas com o intuito de fortalecer vínculos e promover a saúde dos indivíduos. É importante que o reconhecimento dessa atividade por parte dos educadores ocorra a fim de que possam cobrar a assistência a suas crianças de maneira efetiva e com qualidade.

Do total de educadores, $6(35,3 \%)$ afirmam ministrar o conteúdo para seus alunos e a maioria $15(88,2 \%)$ concorda em executar atividades ligadas à promoção da saúde bucal. Quando interrogadas sobre as ações desempenhadas, 11 (64,7\%) citaram realizar com seus alunos bochecho com água fluoretada, educação em saúde e supervisão de higiene bucal.

Dentre as atividades mais utilizadas para a educação em saúde foram citadas a prática da escovação $(76,4 \%)$ seguida por exposição oral $(17,6 \%)$ e utilização de filmes $(6 \%) .14$ (82,3\%) educadoras relataram que as crianças sempre manifestam grande interesse sobre o assunto.

Os cuidados com a saúde bucal podem ser ensinados de maneira lúdica e criativa. Durante as atividades recreacionais, há a possibilidade de abordar o tema de maneira divertida fazendo com que a criança perceba a importância do ato.

Para Tamietti et al. (1998), a educação em saúde deve ser fundamentada em uma pedagogia participativa, com princípios orientadores como: o desenvolvimento da capacidade, competência, criatividade, solidariedade e habilidade para analisar e resolver problemas; o aproveitamento das experiências dos educandos, seus saberes, atitudes, condutas, percepções e interpretações como ponto de partida do processo educativo; a redefinição do papel do educador como facilitador da aprendizagem, em uma relação horizontal com o educando; a utilização de ambientes, para a realização dos eventos educativos, que facilitam as manifestações espontâneas dos participantes; a realização da educação através da problematização e a preferência por técnicas 


\section{(Citinerarius Reflectionis:=" = =

dinâmicas e em grupo, e, finalmente, a valorização da aprendizagem adquirida, não em termos de coisas memorizadas, mas em mudança de comportamento e estilo de vida.

De acordo com Barbosa (2004), a aprendizagem em saúde faz parte da vivência escolar e está presente nas experiências educativas processadas pela escola e inerentes ao seu currículo. Por outro lado não se pode dizer o mesmo da assistência individual e a aplicação de tecnologias, as quais são específicas do setor de saúde e não fazem parte do currículo escolar.

Os educadores também foram indagados quanto ao interesse em desenvolver atividades integradas com a equipe de ESF, a idéia foi bem recebida por $100 \%$ dos educadores que sugeriram várias formas de integração, entre elas: desenvolvimento de projetos, debates, oficinas e palestras.

Em relação a sua própria higiene bucal, 12 (70,5\%) relataram ir regularmente ao dentista, mas ao relatarem a data de sua última visita ao dentista somente $3(17,7 \%)$ realizaram consulta odontológica há menos de um ano; excetuando-se aquelas que realizam tratamento ortodôntico, 2 educadoras.

Em seguida, foram indagadas se acreditavam precisar de uma consulta odontológica, 15 $(88,2 \%)$ relataram estar precisando desta consulta. Afirmaram ainda que ao realizar sua higiene bucal, utilizam creme dental e escova, fio dental, flúor e enxaguante bucal.

Os professores são profissionais que convivem diariamente com as crianças, sendo as pessoas de maior contato com eles depois da família, possuindo assim vínculos não só com os alunos, mas também com os familiares da criança (DALTO; FERREIRA, 1998; SANTOS; RODRIGUES; GARCIA, 2003).

Santos, Rodrigues e Garcia (2003) afirmam que a figura do professor de ensino fundamental exerce grande influência sobre o comportamento dos alunos, pelo contato diário durante longo tempo.

É por esse motivo que é de grande importância que o professor demonstre interesse e dê exemplos de preocupação com a sua própria saúde bucal. O professor é um educador em saúde não só quando desenvolve os conteúdos do currículo, mas também de maneira não formal ao implementar projetos, observar as necessidades emergentes dos alunos ou participando de 


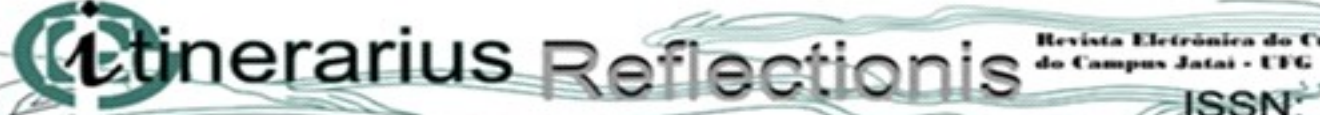
2

\author{
v.11, n. 1,2015
}

campanhas que visem promover o bem estar da comunidade. A educação em saúde na escola interpõe-se nas escolhas dos professores quando selecionam os currículos, ao transmitir conceitos e valores em suas aulas no processo de avaliação, através da metodologia e das situações didáticas criadas por eles.

Apesar de apresentarem nível de escolaridade superior ao encontrado em outros estudos, nas questões referentes ao seu conhecimento sobre a higiene bucal, suas respostas não se diferenciam das respostas de senso comum da população (PAIXÃO, 1979; UNIFER \&SALIBA, 2000), ocorrendo confusão em relação ao papel do fio dental, fluor e alimentos favoráveis aos dentes; sendo que algumas educadoras não reconheciam o enxaguante bucal como parte de sua própria higiene bucal.

\section{CONCLUSÃO}

A análise dos resultados nos mostra que a escola é um importante espaço de informação em todos os aspectos e, inclusive, em saúde bucal, visto que é o local onde há boa interação entre educador e aluno, no entanto, o conteúdo ainda apresenta fragilidades de abordagens durante a formação profissional, fator que dificulta o aproveitamento deste espaço de maneira mais efetiva. $\mathrm{O}$ estudo também nos permite concluir que os professores necessitam e desejam maiores informações sobre o assunto, a fim de abordar com segurança o conteúdo Saúde bucal em sala de aula. E o mais importante é que nesse estudo conclui-se que existe interesse por parte dos profissionais da educação em estabelecer parcerias em projetos com a equipe ESF, sobre Saúde Bucal. 


\section{(tetinerarius 2 v.11, n. 1, 2015

\section{REFERÊNCIAS}

ALALUUSUA, S.; MALMIVIRTA, R. Early plaque accumulation - a sign for caries risk in young children. Community Dent Oral Epidemiol, vol 22, n 5, p273-6, 1994.

BARBOSA, M.S.S. O papel da escola: obstáculos e desafios para uma educação transformadora. Dissertação (Mestrado). 2004. 54p. Universidade Federal do Rio Grande do Sul, Programa de Pós-graduação em Educação. 2004.

BRASIL. Lei . $^{\circ} 9.394$ de 20 de dezembro de 1996. Lei de Diretrizes e Bases da Educação Nacional. LDBEN, 1996 Estabelece as Diretrizes e Bases da Educação Nacional. 1996.

. Constituição (1988). Constituição da República Federal do Brasil: promulgada em 5 de outubro de 1988. Imprensa Oficial. Brasília, DF, 1988.

- Ministério da Educação e do Desporto. Secretaria de Educação Fundamental. Referencial curricular nacional para a educação infantil. Brasília: MEC/SEF, 3vol. 1998.

2004.

- Ministério da Saúde. Diretrizes da Política Nacional de Saúde Bucal. Brasília, 26p,

- Ministério da Saúde. Resolução $N^{o} 466$, de 12 de dezembro de 2012. Dispõe sobre diretrizes e normas regulamentadoras de pesquisas envolvendo seres humanos. Brasília, 13p, 2012. Publicada no DOU n ${ }^{\circ} 12$ - quinta-feira, 13 de junho de 2013 - Seção 1 - Página 59.

DALTO, V.; FERREIRA, M. L. Professores como agentes promotores de saúde bucal. Semina, Londrina, v. 19, p. 47-50, fev. 1998.

FABRE, R.C.; VILELA, E.M.; BIFFI, E.M. Programa de prevenção e educação em saúde bucal para crianças de 3 a 5 anos: um relato de experiência. Rev do CROMG, vol 4, n 2, p 101-7, 1998.

GARCIA, P. P. N. S.; DINELLI, W.; SERRA, M. C. Saúde bucal: crenças e atitudes, conceitos e educação de pacientes do serviço público. JAO - Jornal de Assessoria ao Odontologista, v. 3, n. 22, p. 36-41, 2000.

OMS. ORGANIZAÇÃO MUNDIAL DE SAÚDE. Comissão de Especialistas em Educação em Saúde da Organização Mundial da Saúde. Washington: OMS, 1954. 
PAIXÃO, H. H. Odontologia sob o capital. Dissertação (Mestrado). 1979, 167 p. Belo Horizonte: Faculdade de Educação da UFMG. 1979.

SANTOS, P. A.; RODRIGUES, J. A.; GARCIA, P. P. N. S. Conhecimento sobre prevenção de cárie e doença periodontal e comportamento de higiene bucal de professores de ensino fundamental. Cienc Odontol Bras, São José dos Campos, v. 6, n. 1, p.67-74, jan./mar. 2003.

SILVA, I.O. A creche e suas profissionais: processos de construção de identidade. Em Aberto, Brasília, v. 18, n. 73, 2001.

TAMIETTI, M.B. et al. Educação em saúde bucal para adolescentes: inadequação de uma metodologia. Arquivos de Odontologia, v.34, n.1, p.33-45, jan./jun. 1998.

VASCONCELOS, R. et al. Escola: um espaço importante de informação em saúde bucal para a população infantil. PGR Pós-Grad. Rev. Fac. Odontol., v. 4, n. 3, p. 43-48, 2001. 